\title{
Las aportaciones de la arqueología a la historia de la democracia ateniense*
}

\author{
The contributions of the archeology to the history of the \\ democracy
}

LILIANE LÓPEZ-RABATEL**

\begin{abstract}
Resumen: La democracia ateniense se enmarca desde los orígenes en una comunidad territorial, religiosa, política y arquitectónica. Sus instituciones son bien conocidas por los textos y la arqueología ha puesto al descubierto vestigios de lugares y edificios que permitieron su aplicación. En el marco de este artículo nos preguntaremos si la democracia ateniense se dotó de edificios y de herramientas específicos y, si tal fuere el caso, cómo su hallazgo, en vinculación con los datos proporcionados por los textos permitió avanzar en el conocimiento de su funcionamiento y determinó etapas relevantes en la escritura de su historia.
\end{abstract}

Palabras clave: democracia, arquitectura, Atenas, ágora, sorteo, kleroteria.

\begin{abstract}
The roots of the Athenian democracy were already characterized by a territorial, religious, political and architectural community. Its institutions are well known through written sources, and archaeology disclosed remains of sites that enabled its establishment. The purpose of this paper is to question whether the Athenian democracy was endowed with structures and specific tools. Should it be the case, this paper shall also emphasize how their discovery, associated with the pieces of information provided by written sources, allowed us to progress into the knowledge of its functioning, and shaped milestones for the writing of its history.
\end{abstract}

Key words: democracy, architecture, Athens, agora, sortition, kleroteria.

Los orígenes de la democracia ateniense son tantos míticos como históricos y por lo tanto no permiten definir con certidumbre las etapas por las que, de oligarquía, pasando por la tiranía de los Pisistrátidas, se convirtió el gobierno en democracia.

Fecha de recepción: 05/06/2017. Fecha de aceptación: 08/09/2017.

" Este texto fue escrito en el marco del proyecto de I+D: "La recepción de la filosofía grecorromana en la filosofía y las ciencias humanas en Francia y España desde 1980 hasta la actualidad" FFI2014-53792-R (2015-2017), y del proyecto ANR/DFG «(New) Political representative Claims: A Global View (France, Germany, Brazil, China, India)».

** Investigadora en el Instituto de Investigación sobre la Arquitectura Antigua (IRAA-CNRS-Univ. Lyon 2).

Líneas de investigación: Arqueología antigua, Historia de las instituciones del mundo griego, Historia de los procedimientos y de las herramientas de la democracia antigua, vocabulario y concepción de la ciudad antigua, recepción de la antigüedad en la época moderna y contemporánea. Publicaciones recientes: López-Rabatel, Liliane y Sintomer, Yves (2018, en prensa): Tirage au sort et démocratie. Pratiques, instruments, théories, La Découverte, París; López-Rabatel, Liliane (2017): "Les procédures d'élection et de décision de la démocratie athénienne", en Le vote et la démocratie dans l'Antiquité, Dossiers d'archéologie, $\mathrm{n}^{\circ} 380$, mars-avril 2017, pp. 14-21. Contacto: liliane.rabatel@mom.fr 
Según una tradición que se ha forjado en el siglo V a.C., Teseo es el héroe fundador de Atenas a través del sinecismo, es decir, de la reunión de pequeñas entidades geográficas en una única ciudad, y también el fundador de la democracia ateniense. Tucídides (Guerra del Peloponeso II.15.2) y Plutarco (Vida de Teseo, XXIV) nos cuentan la fundación de Atenas, iniciada por el héroe después de su vuelta de Creta. Destacan no sólo la unificación inicial del territorio y el establecimiento de un culto común, las Panateneas, sino también la formación de un Consejo único y la construcción de un solo Pritaneo. A pesar de que el Pritaneo no es un edificio propio de la democracia, aparece aquí como testimonio del nuevo régimen político, en el que Teseo, según dice Plutarco, se quedó con el mando de las guerras y la custodia de las armas, guardándose la igualdad en todo lo demás. El vivir juntos, el sinecismo, se expresa pues en el umbral mítico de la democracia, por una comunidad territorial, religiosa, política y arquitectónica.

Se plantea entonces la cuestión de saber si, en el rastro de Teseo, la democracia se dotó de edificios específicos y, si tal fuere el caso, qué nos enseñan respectivamente, sobre la aplicación de los procedimientos democráticos, los textos, la organización del tejido urbano y los vestigios arqueológicos, ya se trate de los edificios como sede de órganos del gobierno o del mobiliario cívico.

Al respecto, es preciso tomar en cuenta en conjunto todas las actividades democráticas, desde la publicidad de las leyes, pasando por los modos de distribución de los cargos políticos, por sorteo o elección, los trámites de toma de función y de salida de cargo, y por supuesto, los lugares de reunión de los cuerpos políticos a nivel de los demos o de la administración central y por fin, las diferentes formas de expresar la toma de decisión en el seno del Consejo, de la Asamblea o del tribunal popular.

Es imposible presentar en este marco un estado cronológico de la cuestión, ya que supondría un trabajo historiográfico muy amplio cuyas conclusiones no podrían presentarse brevemente aquí. Intentaré entonces presentar las etapas más relevantes de los hallazgos arqueológicos que permitieron hacer evolucionar el conocimiento del funcionamiento de la democracia ateniense. El trabajo se centrará primero en los edificios que albergaban los cuerpos políticos y, en segundo término, en el equipamiento de la democracia, sin perder de vista que es imprescindible reflexionar al mismo tiempo sobre los lugares, los procedimientos y las herramientas democráticas, siempre confrontándolos con las informaciones literarias, a fin de disponer de una visión lo más clara posible del tributo que se le debe a cada clase de fuente en el proceso de conocimiento de la democracia.

\section{Los lugares y los edificios de las prácticas democráticas}

\subsection{El ágora o las ágoras}

El ágora aparece como lugar de reunión en la poesía homérica, pero después de Homero ningún texto menciona el ágora como lugar de reunión política organizada antes del advenimiento de la democracia. Varios autores admiten, sin embargo, que el ágora de Atenas pudo ser utilizada como lugar de reunión antes de las reformas de Clístenes, apoyándose en un pasaje de Heródoto (I, 59, 4), y en otro de la Vida de Solón (1-3 5) de Plutarco, en los que se relata cómo Pisístrato se hirió a sí mismo y se fue al ágora para que el pueblo le tuviera 
lástima. Se reunió el pueblo en asamblea y le otorgó al tirano 50 guardaespaldas, armados de mazas. El autor utiliza la palabra "ágora”, lo que conduce, en esa época del arcontado de Pisístrato, fechado entre 522 y 511, a la cuestión espinosa de la ubicación del ágora o, mejor dicho, de las ágoras de Atenas, cuestión que está vinculada tanto al mito de la fundación de la ciudad como a la edificación del Pritaneo.

De este edificio, mencionado en la Vida de Teseo, no existe probablemente ningún vestigio. Aparece por primera vez en un decreto a propósito de la sitesis en el Pritaneo, que se data entre los años 440 y 432 a.C. (IG I ${ }^{3} 131=S E G$ 46.2264). Aparte de los textos de Tucídides y de Plutarco, el Pritaneo (Miller, 1978) se menciona con frecuencia a lo largo de la época clásica, en relación a la institución de la sitesis, el honor vitalicio a ser invitado a comer en el Pritaneo a costa del estado, a cambio de actos benéficos hacia la ciudad. Los textos proporcionan informaciones poco explícitas en cuanto a su ubicación que ha sido objeto casi siempre de debates. En la Constitución de los Atenienses, Aristóteles (3.5), evocando el tiempo de Dracón, dice que el Pritaneo estaba cerca del Boukoleion y del Epilykeion. En el primero se sentaba el arconte-epónimo, en el segundo el arconte-rey, el Basileus, y en el último el polemarco. A estos edificios antiguos, que por lo visto estaban cerca los unos de los otros, hemos de añadir el Theseion, que fue dedicado por Cimón en el año 476/5 al héroe fundador (Plutarco, Vida de Cimón 8.5-6) después de haber traído sus huesos desde la isla de Esciros, siguiendo los preceptos de un oráculo délfico de 476/5 a.C. Las fuentes clásicas establecen un vínculo de proximidad entre este santuario con el Pritaneo pero dando a veces informaciones contradictorias o erróneas sobre la ubicación de ambos edificios, aumentando la confusión. Tucídides (VI, 61, 2) lo ubica en el centro de la ciudad mientras que el autor de la Constitución de los Atenienses lo sitúa al oeste de la Acrópolis $(15,4)$ y Plutarco (Vida de Teseo, 36.4) y Pausanias (I, 17, 1-6), al lado del Gimnasio de Ptolemeo, cerca del ágora. Es preciso tener en cuanta también el Basileion, mencionado solamente por el lexicógrafo Julio Pólux de Naucratis (VIII 111 y IX 40), que vivió en el siglo segundo d.C. Lo ubica por error en la Acrópolis pero, siendo sede del arconte-rey, debía estar al lado de los edificios citados antes. Además de plantear problemas de denominación de los edificios -en los que no se puede profundizar aquí- la zona en la cual se encontraban todos ellos nunca ha podido ser definida con certidumbre, pero sí es considerada ahora, por la mayor parte de los investigadores, como el ágora arcaica de Atenas. Sin embargo, es preciso distinguir entre el lugar donde se asentaron los primeros edificios cívicos de Atenas y lo que podría ser propiamente un ágora, es decir, un lugar destinado a reuniones informales del pueblo o a sesiones más formales, conforme a las distintas formaciones políticas, en edificios idóneos. Ninguna clase de fuente documenta la existencia de tal ágora en la época arcaica. En una referencia única, citada por Harpocration (s.v. Pandèmos Aphroditè, atribuida a PseudoApolodoro, Sobre los dioses, siglo II a.C.), aparece la expresión "ágora antigua", de la cual se ha deducido la existencia de un ágora arcaica y de allí, su desplazamiento bajo los Pisistrátidas a la zona del Cerámico. A partir de estos indicios, algunos situaron el Pritaneo en la Acrópolis y el ágora entre la Acrópolis y el Areópago (Martin, 1951, 211 n.5; Oikonomides, 1964, 1-50). Otros pensaban que el ágora arcaica se encontraba al este de la Acrópolis, sin más pruebas y sin posibilidad de verificarlo con vestigios arqueológicos. Las contradicciones de las fuentes pueden explicarse tanto por la falta de necesidad de los autores coetáneos de precisar algo que todos tenían ante los ojos o, para los más tardíos, por el hecho de que habían desaparecido ya testimonios que les permitiesen ubicar los edificios con certeza. 
Sobre la forma de los edificios los textos no enseñan nada. En el Pritaneo se guardaba el fuego sagrado de la ciudad y se rendía culto a Hestia, por lo que se puede suponer que presentaba una determinada forma de templo, ya que no se puede decir que existiera una sola forma específica. También se alojaba a los prítanes, que gozaban del honor de la sitesis y a los honrados de fuera. Según lo que se puede observar de los pritaneos que se han conservado en otras partes del mundo griego, podría haber sido una casa grande con uno o varios comedores (Thompson \& Wycherley, 1972, 47-48). Porque sirvió, además, hasta finales del siglo IV, de tribunal para homicidios, tendría una zona descubierta, imprescindible en los tribunales que juzgaban aquellos, para que no se contaminaran los jurados por la mancha del acusado.

El descubrimiento in situ en el año 1980 de una estela, datada de 250/249, erigida en honor de una sacerdotisa de Aglauros permitió localizar su santuario (Dontas, 1983, 57-63). Ya que constituía en algunos textos que he citado un punto de referencia espacial para los edificios arcaicos, se ha podido de hecho revisar parte de la topografía ateniense localizando entonces sin dudas al noreste de la Acrópolis la zona del ágora arcaica con el Boukoleion, el Basileion, el Epilykeion, el Prytaneion y el Theseion (Miller, 1978, 38-54 y Leslie Shear, 1994, 225-248, plano 226).

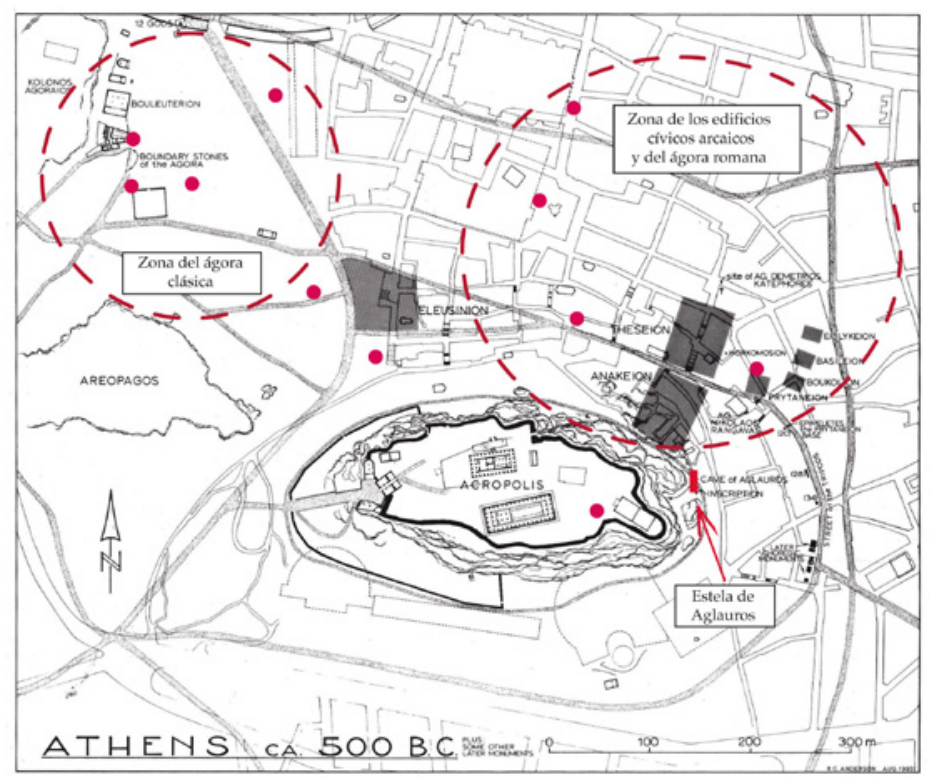

FIGURA 1:

Atenas: lugares de descubrimiento de los klèrôtèria (ágora clásica y ágora romana) y de la estela de Aglauros. Mapa de L. López-Rabatel (a partir de Leslie Shear, 1994, p. 226, fig. 1).

La cuestión de la ubicación de estos primeros edificios públicos está por otra parte vinculada al desarrollo del ágora del Cerámico, llamada así por los talleres de alfareros que se encontraban en el entorno, es decir el ágora clásica.

Las excavaciones que se hicieron a partir de los años 1930, bajo la responsabilidad de la Escuela Americana de Estudios Clásicos, pusieron al descubierto en la parte oeste del ágora 
edificios cívicos de tamaño bastante importante, que podrían ser los archeia que aparecen en los textos (Demosthenes, Cuarta Filípica, 53). Se construyeron a lo largo del siglo VI, quizá en la época de Solón, Pisístrato y también Clístenes (Thompson \& Wycherley 1972, 126-128).

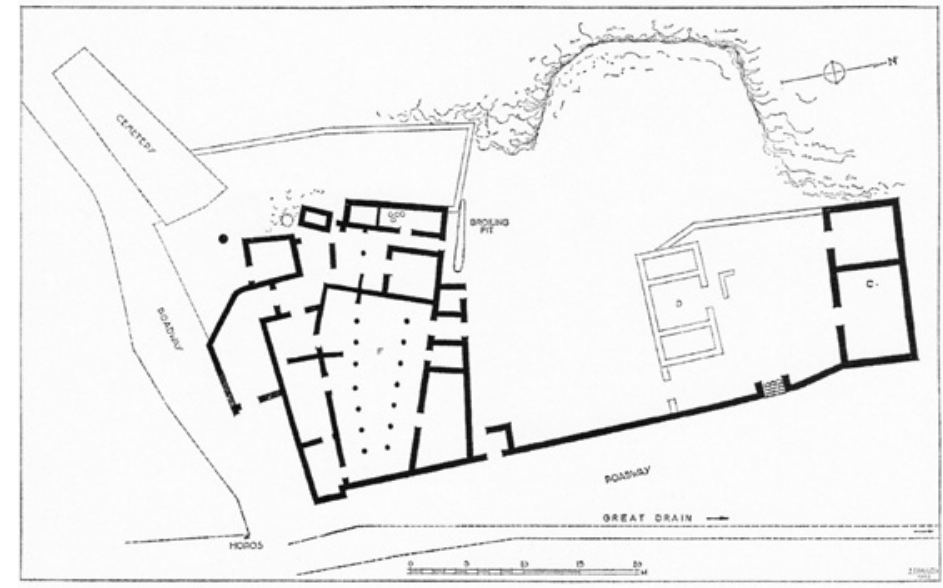

FIGURA 2:

Primeros edificios públicos al suroeste del ágora (Thompson, Wycherley, 1972, p. 26, fig. 8).

No sabemos si estos edificios sustituyeron a otros que tenían el mismo uso y que podrían haber estado antes cerca de la zona del Pritaneo. Lo cierto es que el ágora del Cerámico empezó a ser cada vez más ocupada, tanto por edificios públicos profanos como por edificios públicos religiosos. Después de los archeia, la organización del festival de las Panateneas por el tírano Pisístrato en el año 566 a.C. provocó la construcción, en el trazado de una calle antigua, de la Vía Panatenáica. La impronta de los Pisitrátidas se lee también en los vestigios del altar de los Doce Dioses cuya identificación siempre fue evidente y en los de la Fuente Enneakrounos de la que se sabe que fue erigida en la misma época pero cuya localización ha sido objeto de muchas discusiones (Thompson \& Wycherley 1972, 129-136 y 197-203).

¿Qué pasó entonces con el ágora arcaica? Algunos piensan que en Atenas hubo dos ágoras con un uso más o menos contemporáneo (Oikonomides, 1964, 3 n.14), otros, que se abandonó por completo el ágora arcaica y, hasta el descubrimiento de la estela del santuario de Aglauros, se sostuvo la hipótesis de que podía haberse encontrado al oeste de la Acrópolis.

Lo más probable es que no existiera ninguna ágora arcaica como lugar pensado para reuniones del pueblo, pero sí una zona en la cual se ubicaron los primeros edificios públicos sagrados de la ciudad, mientras que en la zona del Cerámico, se edificaron muy temprano edificios cívicos públicos. Se hubiera trasladado entonces parte de los edificios cívicos del ágora arcaica al nuevo emplazamiento y siguieron en uso algunos de los santuarios que se encontraban allí. Los textos de la época clásica y helenística, lo veremos más adelante, documentan la utilización de la zona para actividades políticas a lo largo de la historia de Atenas. Se puede entonces proponer la hipótesis verosímil de que el ágora ateniense estuvo situada desde el principio en el lugar donde se desarrollaría después el ágora clásica. 


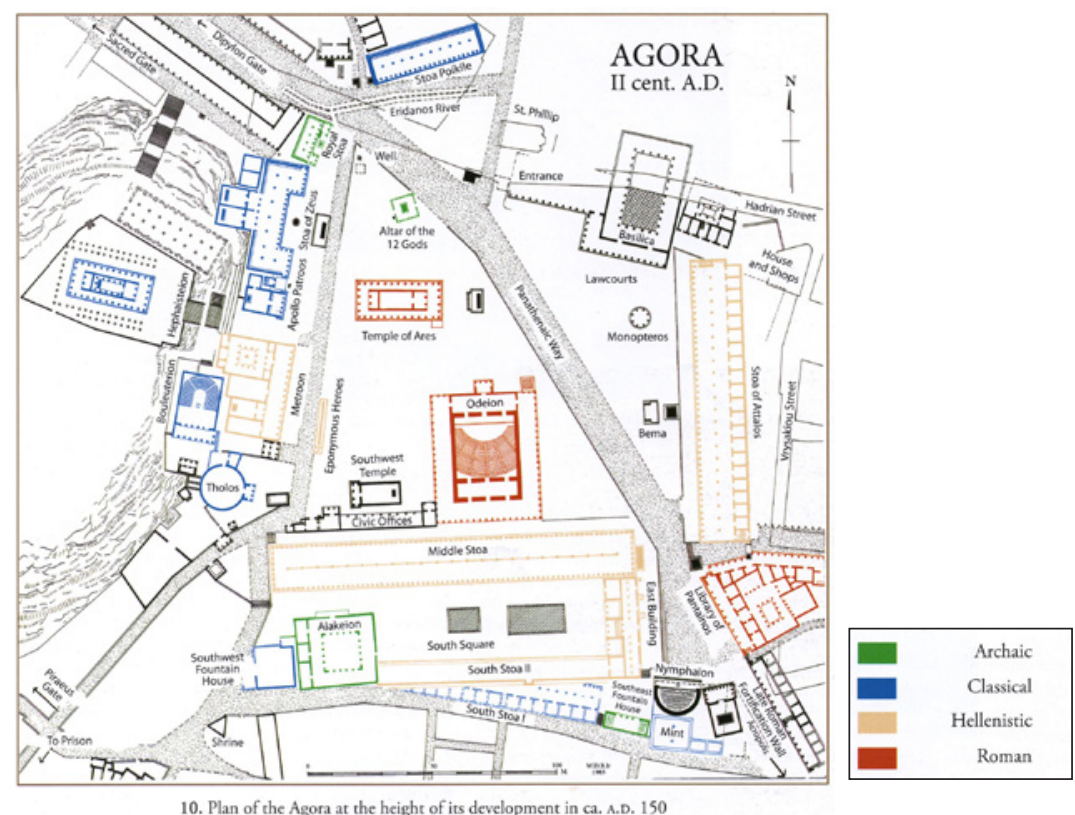

FIGURA 3:

El ágora clásica, desarrollo desde la época arcaica al siglo II d.C. (in Mauzy 2006, p. 9).

\subsection{El Bouleuterion}

Cerca de los archeia, alrededor del año 500, se construyeron en el borde oeste del ágora el llamado Viejo Bouleuterion y probablemente, más al norte, la Stoa Basileios para el arconte-rey, el cargo más importante -heredado de la monarquía- cuya sede se desplazó desde el ágora arcaica. El Bouleuterion era la sede de los Quinientos (miembros del Consejo), identificado sin dificultad desde el principio aunque su plano no se puede reconstruir con seguridad por haberse construido sobre él después el Metroon y los Archivos en 140 (Thompson \& Wycherley 1972, 29-38). También se reconoció fácilmente en 1934 el Tholos gracias a fuentes literarias tardías que lo describen como un edificio redondo (Escolios a Demóstenes, Sobre la falsa embajada 249; Etymologicum Magnum s.v. Tholos). En él comían los 50 prítanes entre los cuales un tercio se quedaba a dormir. Es casi seguro que se construyó en el lugar de uno de los edificios públicos arcaicos (F) que formaban parte de los archeia, cuya distribución constaba de varias habitaciones y una cocina. Los vestigios indican que fue rehabilitado en los años 460 .

Más dificultoso resulta entender la rehabilitación que se hizo alrededor de los años 415-406 en lo que los modernos llamamos el Nuevo Bouleuterion. El edificio es más pequeño, mide 22 × 16 m en vez de los 23 x 23 de antes. Los arqueólogos no coinciden sobre la restitución de la organización interior. El estudio de los vestigios muestra que se añadieron gradas entre 224/3 et 201/200, seguramente para poder alojar al número creciente de consejeros, debido a la creación, entre 307 y 201/200, de dos tribus adicionales. 
En este caso se aprecia que los textos y los vestigios se informan mutuamente. Igual que en el tiempo de Teseo, el Consejo es objeto de una especial atención debido a que era el órgano esencial de la democracia. Es el primer edificio que se erigió en el ágora clásica, lo que puede sugerir que no había en el ágora arcaica un lugar idóneo para las reuniones de los 500 consejeros.

El caso de Atenas es único en el mundo griego en su programa de alojamiento de esta institución democrática por excelencia. La forma del Tholos no se encuentra en ningún otro lugar para alojar a los prítanes aunque el tipo de rotonda es conocido pero con otra función, en Epidauro o Delfos por ejemplo. La segunda particularidad es la existencia simultánea del Tholos y del Pritaneo, sin que sepamos con certeza si el último servía para los honrados a la sitesis y la primera para los prítanes, ya que se encontrarían más cerca de los otros lugares de reunión como la Pnyx para la Asemblea, o de los tribunales.

\subsection{Los pórticos}

Algunas fuentes indican que los pórticos situados en el ágora eran la sede de magistrados o de reuniones del tribunal. La Stoa Basileios, es decir el Pórtico Regio fue, según dice el autor de la Constitución de los Atenienses $(3,5)$ la sede del arconte-rey que residía antes en el Boukeleion.

La Stoa Poikilè, o pórtico Colorado, que a veces no se ha podido distinguir del Pórtico Regio a partir de la información que proporcionaban los textos, era una especie de museo o de pinacoteca en la que se exponían carteles de madera pintados relatando episodios famosos mitológicos o históricos (Esquines, Contra Ctesifonte 186; Escolios a Aristófanes, Lysistrata 678; Pausanias, I, 15.1-16.1). Sabemos que este mismo pórtico sirvió para actividades judiciales, tanto para arbitrajes públicos (Demóstenes, Contra Stefanos I, 17 y Contra Neera, 94) como para juicios: tal vez el de Sócrates en el 399 a. C., que aún es una cuestión debatida y, a mediados del siglo IV a.C. están documentados otros dos juicios, al menos uno de ellos con 500 jurados $^{1}$.

Por tanto, si las fuentes literarias no mencionan ningún lugar ni edificio en el ágora destinado a las reuniones del pueblo, sí vemos que se desarrollaban en ella actividades políticas en los pórticos que la rodeaban, pero cuya función no estaba precisamente definida para cada edificio. La Stoa Basileios era la sede del arconte-rey, que tenía entre otras una prerrogativa muy importante, la judicial, y la Estoa Poikile sirvió también para juicios a pesar de que no era su destino principal. Los textos no dan información sobre su ubicación, ni tampoco sobre su forma, pero las excavaciones que se han hecho desde el año 2010 en el sitio del pórtico, bajo la dirección de The Agora Excavations, confirman la identificación del edificio y proporcionan datos sobre sus dimensiones (Agora reports 2010, 2011,2012) que permitían acoger a 500 jurados a mediados del siglo IV.

1 En una inscripción datada de 341/0 (Clinton, Eleusis 152), un contrato para la terminación de obras en el Telesterion de Eleusis (una gran sala para la iniciación a los misterios de Eleusis), aparece la mención de un juicio ante un tribunal de 500 jurados en la Stoa Poikile. En un acto de los Amphictiones (los magistrados encargados de la administración del tesoro de la liga de Delos) de mediados del siglo IV a.C. (IG II ${ }^{2}$ 1641b), aparece un hombre absuelto después de su juicio en la Stoa Poikile. 


\subsection{El perischoinisma}

A lo largo del siglo $\mathrm{V}$, el ostracismo, que estuvo en vigor, según los textos, desde el año 487 al 416, fue el único procedimiento democrático que reunía al pueblo como entidad política en el ágora. El historiador Filocoro (328 F 30), que vivió en el siglo III a.C., explica que se cerraba una parte del ágora con tablas de madera y que para entrar había diez puertas, una por tribu, por las que los ciudadanos pasaban para depositar su ostrakon, en el que estaba escrito el nombre de la persona que querían que fuera desterrada de Atenas. La palabra perischoinisma no aparece en las fuentes de la época clásica en las que sólo se usa el verbo perischoinizesthai, rodear (con cuerdas u otro dispositivo provisional) ${ }^{2}$. Lo emplea Plutarco, en la Vida de Aristides (7.5-6) y en la Vida de los diez oradores (847a). Para él era una parte del ágora en la que se formaba un recinto con una barrera, al lado de la estatua de los Doce dioses. También aparece la palabra en el Onomasticon de Julio Pólux y en las obras de otros lexicógrafos, de allí el nombre utilizado por los modernos.

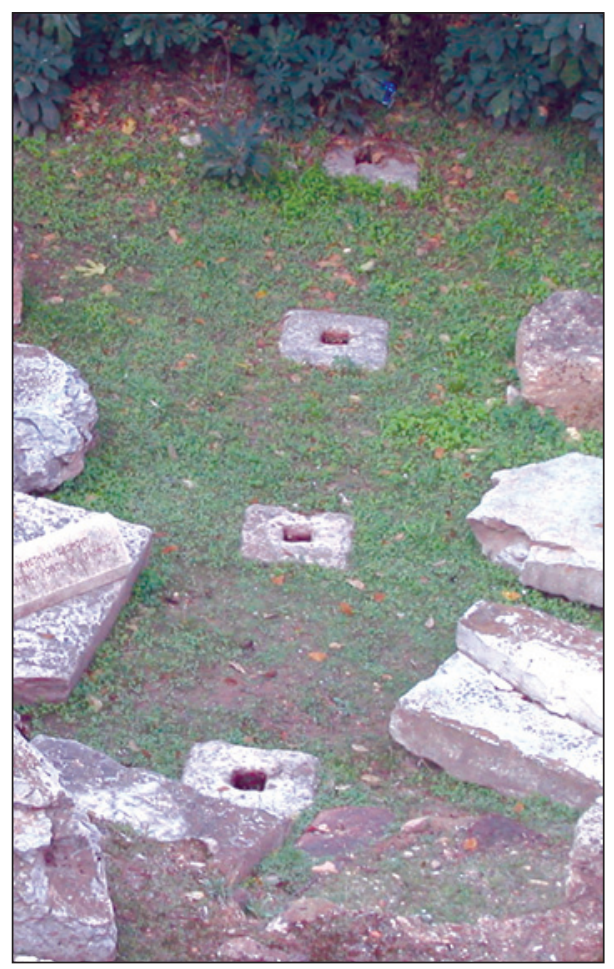

FIGURA 4:

Vestigios de los huecos hallados al noreste del ágora (C J. Ch. Moretti), del supuesto perischoinisma.

2 Este tipo de dispositivo provisional lo menciona también Demóstenes, Contra Aristogitón, I 22-23, a propósito de las barreras que protegían a los miembros del Areópago sentados en el Pórtico Real. 
Con estas escasas informaciones, no se podía esperar mucho de los vestigios arqueológicos. En los años 70, al norte del ágora, fueron descubiertos una serie de huecos en el suelo, dispuestos en orden; se pensó que habrían podido servir para una barrera ligera que formara la entrada del ágora. La estratigrafía permitió establecer la datación en la primera mitad del siglo $\mathrm{V}$ a.C. Apareció también una línea de cinco bases, más o menos cuadradas, de piedra caliza de $47 \mathrm{~cm}$ de lado y de $38 \mathrm{~cm}$ de profundidad, separadas las unas de las otras por un espacio de $1.85 \mathrm{~m}$. Se divisaba en el centro un hueco más pequeño en el que podían haberse insertado postes de madera para sostener una estructura ligera. Esas bases, que se datan de los alrededores del año 450, se interpretaron inicialmente como elementos de la línea de partida de una pista de carrera, una aphesis tal como las de Priene, Corinthos o Epidauro (Valavanis, 1999).

Conectándola con las 10 tribus se restituyeron diez espacios. Un arqueólogo italiano, Enzo Lippolis, en el año 2000, intuyó que podría ser parte del perischoinisma y planteó la hipótesis de la existencia de una zona al norte del ágora destinada a las operaciones de voto en el siglo V. Las excavaciones realizadas entre 2011 y 2013 han puesto al descubierto otras bases de la misma categoría, delimitando esta vez un rectángulo de $12 \mathrm{~m}$ x $15 \mathrm{~m}$. Se puede ahora datar más precisamente este dispositivo, que se remontaría a los años 475-450 y que dejó probablemente de ser utilizado alrededor del 430-420 (Agora reports 2012 \& 2013). E. Lipollis reitera en un estudio reciente (Lipollis, en prensa) su hipótesis favorable a la identificación del perischoinisma, si bien no creo que se pueda afirmar con total certeza. El espacio, de $180 \mathrm{~m}^{2}$, resulta pequeño para acoger a todos los magistrados que dirigían las operaciones de ostracismo, los arcontes y según dice Filocoro, el Consejo, que sería más bien los prítanes, que ya serían bastante numerosos; y ello dando por sentado que no cabían a la vez los 6.000 ciudadanos del quórum para validar el proceso. Habría también que almacenar los recipientes para depositar los ostraka. Podía ser un lugar de transición que no corresponde, sin embargo, a los imperativos de la organización del cuerpo cívico en diez tribus, ya que sólo se pueden restituir 9 entradas entre los 10 postes (López-Rabatel, en prensa-a).

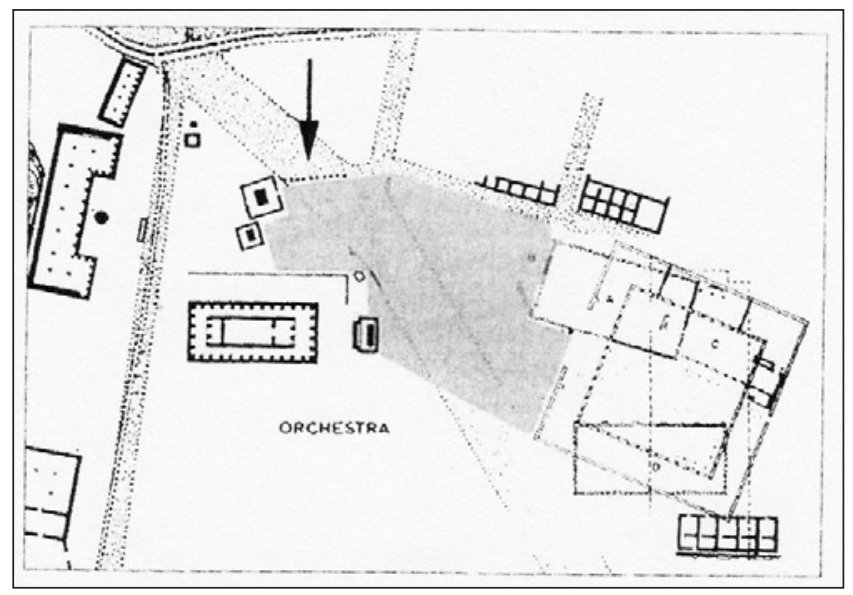

FIGURA 6:

Noroeste del ágora clásica, con la zona del supuesto perischoinisma en gris y la barrera de acceso, indicada por la flecha (Lippolis 2006, p. 47, fig. 5). 


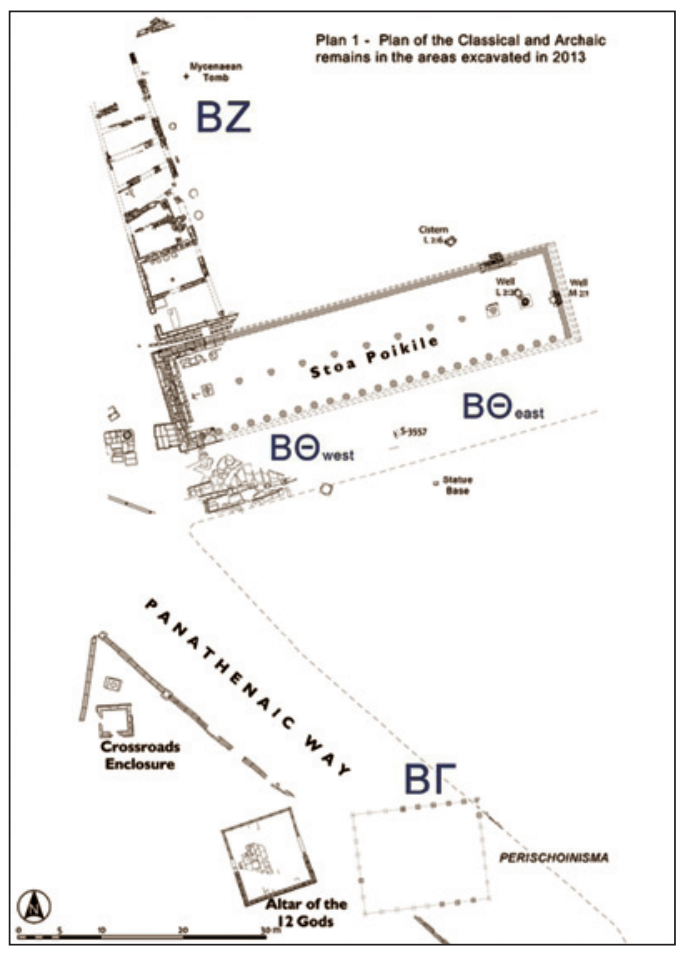

FIGURA 7:

Vestigios del supuesto perischoinisma in Agora 2013 - Preliminary report, p. 5.

Los ostraka proporcionan más información sobre la institución del ostracismo, ya que los nombres grabados confirman los datos de las fuentes textuales, puesto que revelan casos que no están documentados en ninguna otra parte. El hallazgo en las pendientes de la Acrópolis de ostraka con el nombre de Temístocles (471) que no fueron utilizados nunca y además repartidos en 18 series grabadas por la misma mano, llevan a preguntarse sobre la cuestión de la manipulación de los ciudadanos.

Este caso, que trata sin embargo de una de las instituciones democráticas más conocidas del siglo V por los textos, ilustra las dificultades con las que puede toparse el investigador a la hora de relacionar aquellos con los vestigios arqueológicos. Es, por supuesto, un caso muy particular, dado que se trata de un dispositivo temporal pero, por eso mismo, es de cierta importancia, ya que plantea la cuestión del vínculo de algunos procedimientos de la democracia con su asentamiento arquitectónico.

\subsection{La Pnyx}

Aparte del recinto evanescente dedicado al procedimiento del ostracismo, el demos de Atenas se reunió casi durante toda la época clásica en un lugar conocido desde siempre por varios textos como la Pnyx. En 1765, R. Chandler (Chandler, 1806) la identificó con 
lo que se consideraba como un edificio de espectáculo situado en la pendiente noroeste de la colina situada al oeste de la Acrópolis. Las excavaciones y los estudios arqueológicos han permitido distinguir tres fases en el desarrollo del edificio cuyos detalles están siendo todavía debatidos. Las reconstrucciones que se han propuesto han sido criticadas con frecuencia, pero el monumento nunca ha dejado de llamar la atención por el papel que desempeñó en la práctica de la ideología democrática.

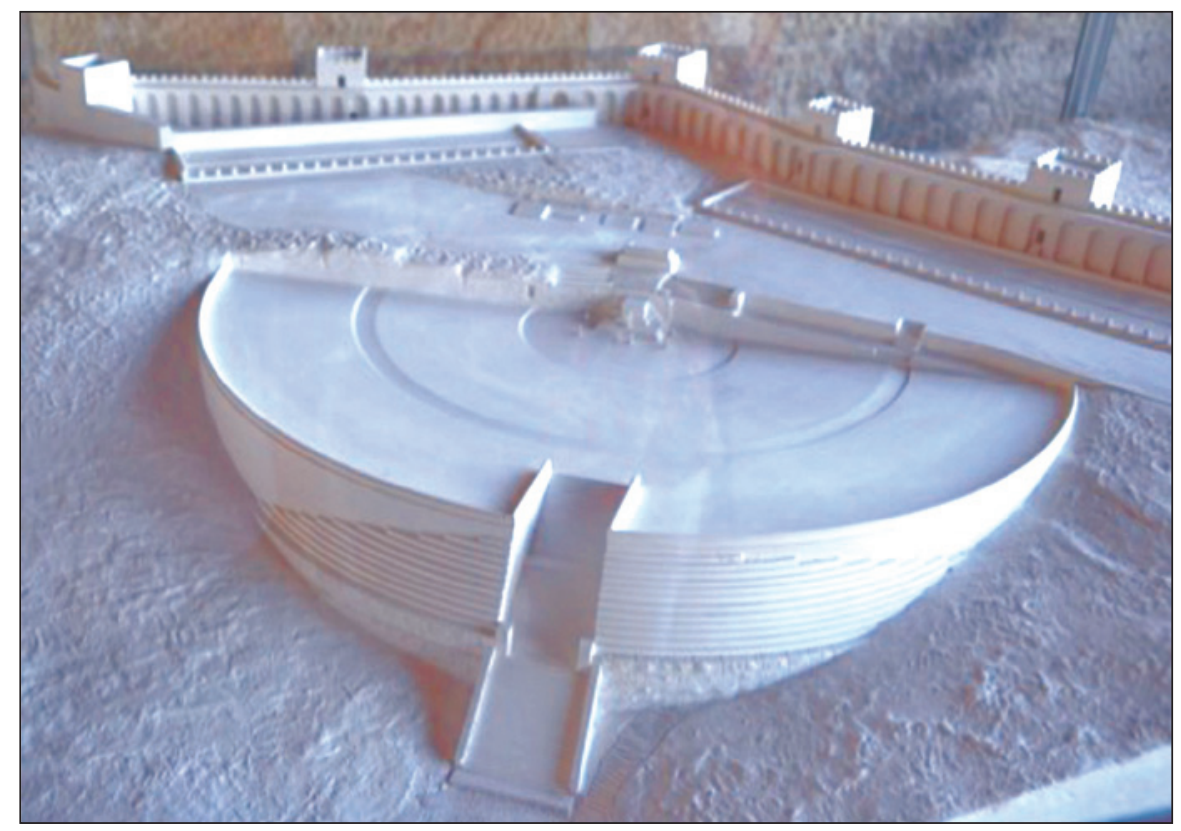

FIGURA 8:

Reconstrucción de la Pnyx (tercer estado). Maqueta expuesta en el Museo del Ágora, Atenas. ㄷ L. López-Rabatel

La evolución de la orientación del edificio expresa la voluntad de las autoridades de ofrecer a la Asamblea un sitio donde cerca de 6.000 ciudadanos pudieran escuchar a los oradores y expresar su opinión mediante un voto a mano alzada. Era necesario entonces que los presidentes de las sesiones, los prítanes o los proedros, pudieran evaluar (y no contar con precisión) cómodamente los votos. Las últimas hipótesis de reconstrucción del edificio propuestas por J.-Ch. Moretti (Moretti, en prensa) tienen en cuenta ese aspecto práctico de la actividad democrática. No se puede sin embargo resolver actualmente la cuestión de la distribución por tribu de los ciudadanos en el seno de la Asamblea, ni tampoco dónde se desarrollaban los votos secretos para otorgar el derecho de ciudadanía. Los textos no son especialmente locuaces al respecto y la arqueología ayuda poco. Quizá podían tener lugar fuera del recinto en una zona equipada de manera provisional, tal como se organizaban los procedimientos de ostracismo en el ágora. A no ser que se realice una nueva campaña de excavaciones, estos problemas quedarán de momento sin solventar. 


\section{Los vestigios de las herramientas de la democracia}

Para seguir con el equipamiento de la democracia, hablemos ahora de los medios materiales utilizados para la expresión de la opinión individual y la distribución de los cargos.

Hemos de precisar que en el Consejo y en la Asamblea se votaba a mano alzada o con fichas o discos de bronce con un vástago hueco o sólido, y sólo con ellos en el Tribunal del pueblo. Se recurría al voto a mano alzada en la Asamblea para elegir a algunos magistrados, para expresar opiniones a propósito de una propuesta de decreto en la Asamblea y en el Consejo. El voto secreto con fichas se utilizaba en el tribunal para votar la culpabilidad o la inocencia de un acusado y para establecer -en caso necesario- la pena para el condenado. También se procedía a la votación secreta antes de las reuniones de la Asamblea para la concesión de la ciudadanía a extranjeros que se habían caracterizado por sus acciones benéficas a favor del Estado.

Algunas fichas llevaban grabada la leyenda psephos demosia, es decir, "ficha del pueblo" o "voto público", acompañada a veces por una letra estampada. Se han hallado unas cincuenta fichas a lo largo de las excavaciones del ágora, desde los años 1930: 20 en la zona del Bouleuterion y de la Tholos, 10 en la zona noreste y unas 20, esparcidas en la plaza. Están casi todas datadas de la segunda parte del siglo IV y algunas del siglo III $^{3}$. Fueron identificadas fácilmente gracias a los textos y en particular al pasaje de la Constitución de los Atenienses en la que se describen estos objetos y, recíprocamente, el hallazgo permitió tener una imagen concreta de lo que sólo se podía imaginar a partir de los textos. No se puede detallar en este marco las características de las diferentes series que se han podido establecer entre las que destaca un elemento importante. Las fichas que no llevan la leyenda psephos demosia proceden de la primera zona mientras que las demás se encontraron en el área noreste.

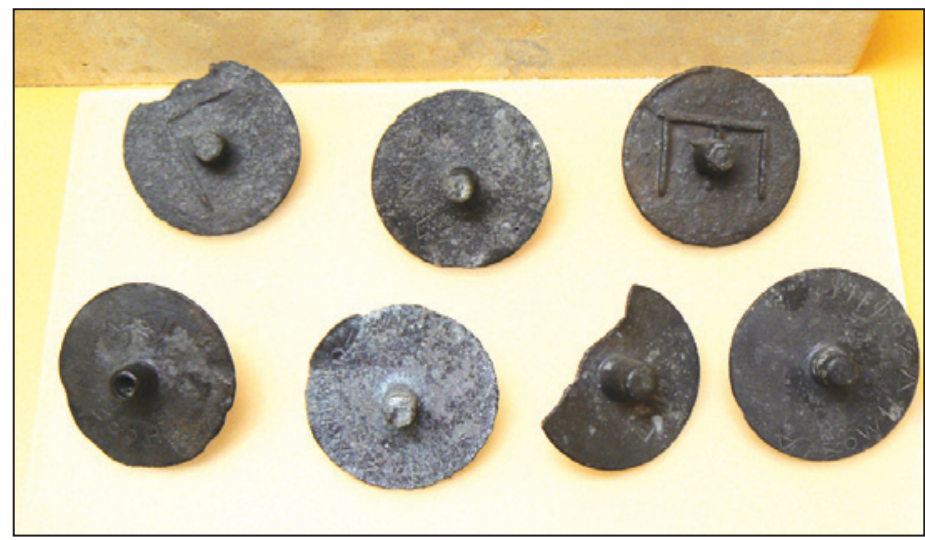

FIGURA 9:

Fichas para el voto. Museo del Ágora, Atenas. (C) L. López-Rabatel.

3 Veáse para las referencias de las ediciones del material: López-Rabatel (en prensa-a). 
Mabel Lang (Boegehold et al., 1995, 82-90), experta en ese material arqueológico, llegó a la conclusión de que las fichas sin leyenda pertenecían al mobiliario de la Boulé, por el lugar de descubrimiento y también porque, por una parte, se quedaban en el recinto del Bouleuterion y, por otra parte, porque al conocerse todos los Consejeros no era necesario protegerse contra los fraudes. Por el contrario, en el tribunal, cuya composición variaba cada día, precisaba distribuir a los jurados fichas autentificadas por un sello oficial, tal como se hizo con las chapas de los ciudadanos utilizadas en las máquinas de sortear, los pinakia. En éstas venían grabados, además de los tres elementos de identidad, sellos como el búho o la Gorgona como garantía de autenticidad (Kroll, 1972).

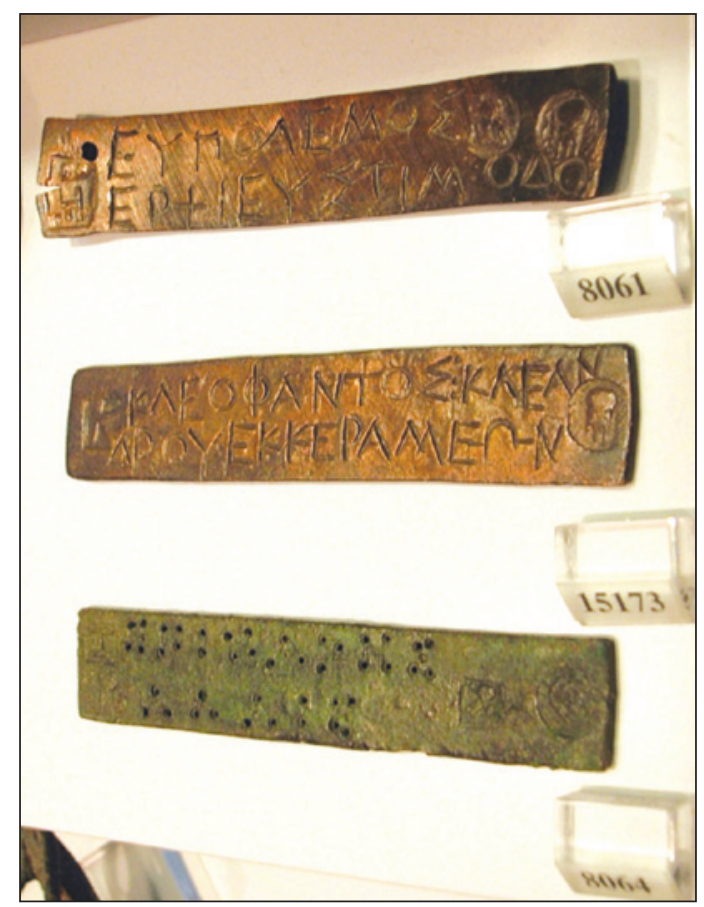

FIGURA 10:

Pinakia (chapas de identidad). Museo del Ágora, Atenas. (C) L. López-Rabatel.

Se puede entonces establecer la hipótesis, gracias a la arqueología, de que las autoridades instituyentes concibieron un sistema de control que se aplicaba a todo tipo de material democrático. El de las fichas de voto resulta un eslabón de la cadena procedimental compleja que conoció su culminación en el último cuarto del siglo IV en el ámbito del tribunal popular, para garantizar la legitimidad de la selección de los jurados cotidianos.

Un ejemplo relevante de la aportación de la arqueología al conocimiento de la democracia es el caso del equipamiento del sorteo utilizado a lo largo de la época clásica y más allá, como veremos. Se hallaron a finales del siglo XIX estelas de mármol cuya primera identificación como dispositivo de medida del tiempo no pudo ser cuestionada hasta que 


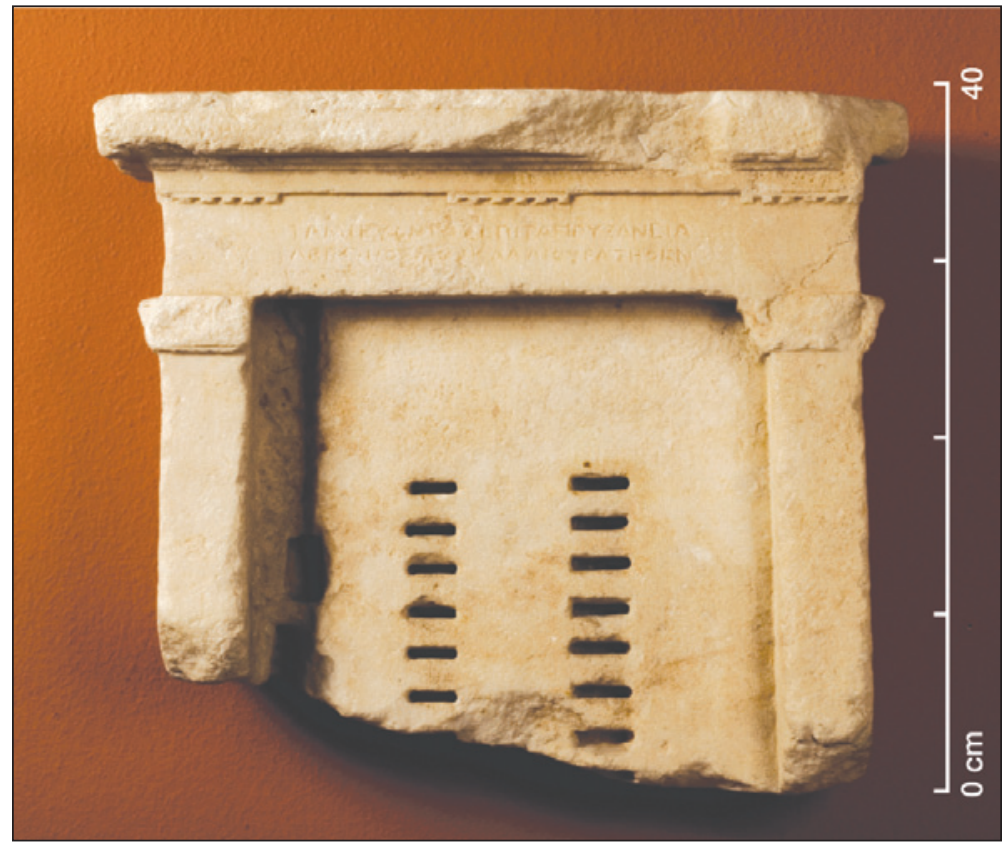

FIGURA 11:

Kleroterion de pequeño tamaño, Museo epigráfico de Atenas, (C) J. Ph. Collet (EfA).

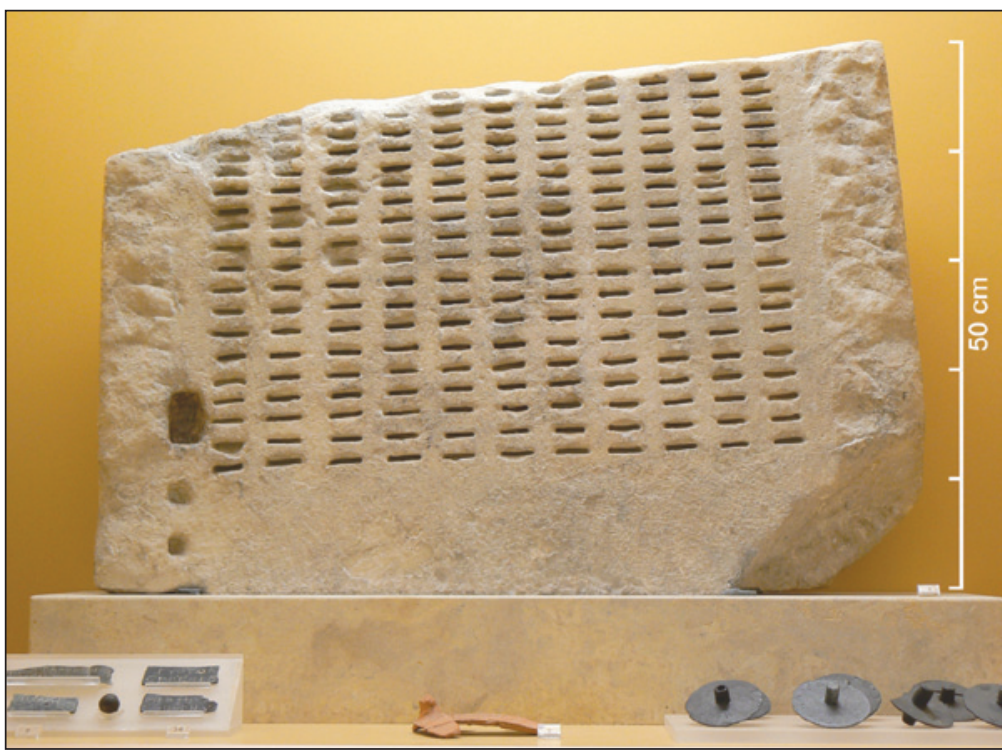

FIGURA 12:

Kleroterion de gran tamaño, Museo del Ágora, Atenas, (c) L. López-Rabatel. 
se descubrieron, en los años 30 del pasado siglo, en las excavaciones del ágora y de sus alrededores, otros ejemplares de dicha máquina. Sterling Dow (Dow, 1937), a quien se debe la primera síntesis sobre el asunto, supo vincular fragmentos que llevaban en la cara anterior líneas de ranuras dispuestas en columnas con la palabra "kleroterion", "máquina de sortear", que aparecía en la inscripción de la cara posterior (Meritt \& Traill, 1974, n 220 y 221) . $^{\circ}$ S. Dow consiguió pues identificar estas estelas como los kleroteria mencionados en la Constitución de los Atenienses, descubierta a finales del siglo XIX. La palabra kleroterion era conocida pero no se había podido hasta ahora relacionar con el objeto.

Gracias al estudio de los vestigios que hice en colaboración con mi compañero arquitecto Nicolas Bresch ${ }^{5}$, siguiendo la estela de Sterling Dow ${ }^{6}$, se han podido establecer criterios para una clasificación de las máquinas y entender mejor qué instituciones utilizaban tal o cual tipo de máquina. A pesar de las dificultades procedentes del corpus de fuentes a disposición (es

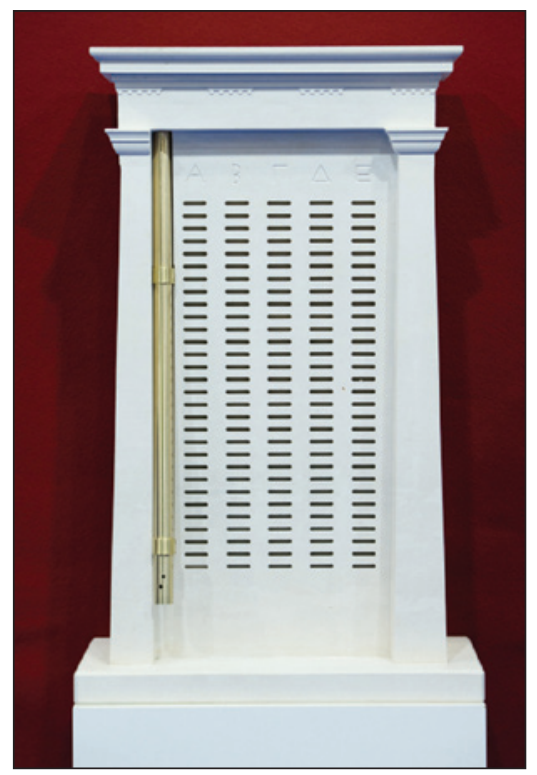

FIGURA 13:

Reconstrucción en piedra de un kleroterion operativo.

(C) Clément Mahoudeau, IRAA, CNRS Photothèque.

4 En esta inscripción se pudo restituir la palabra "kleroterion" a partir de otro fragmento, el único testimonio epigráfico en el que se puede leer claramente.

5 N. Bresch, arquitecto-ingeniero en el Institut de Recherche sur l'Architecture Antique (IRAA), CNRS-AMULyon 2, despacho de París, a quien quiero agradecer especialmente su más firme y total colaboración en todo momento.

6 Este trabajo se hizo en el marco de una tesis doctoral (López-Rabatel, 2011). Estoy preparando con la colaboración de N. Bresch la publicación del corpus entero de los kleroteria, que consta de fragmentos inéditos que me fueron liberalmente transmitidos por J. Kroll, quien heredó del dossier de S. Dow, y por J. Camp, director de "The Athenian Agora Excavations", con el acuerdo de la 1ª Eforia de Estudios Clásicos del Ministerio de Cultura griego (= Dirección regional de la arqueología). 
decir, una distorsión cronológica importante entre las chapas, los pinakia, que se remontan a la época clásica; los textos que cubren la época clásica y llegan hasta la época romana, y los vestigios de las estelas del siglo II a.C., por las que se pueden datar con certeza), hemos tratado de reflexionar sobre las modalidades de uso en las distintas instituciones y los lugares en los que pudieran haber sido instaladas. Teniendo en cuenta el número de columnas y de líneas de ranuras, se determinó que unos kleroteria habían sido utilizados para el sorteo de los jurados del tribunal popular y otros para el sorteo de los consejeros o de la mayoría de los cargos políticos que eran distribuidos por sorteo. Cotejando la Constitución de los Atenienses mediante sesiones de arqueología experimental sobre modelos que N. Bresch realizó a partir de las hipótesis de reconstrucciones que pudimos concebir, parece que se ha podido entender bastante bien el dispositivo de salida progresiva de las suertes que se introducían en un embudo excavado en el entablamento de las estelas. Las experimentaciones siguen ahora con un kleroterion de piedra caliza que fue realizado por un robot escultor, lo que permite trabajar en condiciones más parecidas a las de la Antigüedad? .

En cuanto al estudio iniciado por J. Kroll sobre las chapas y continuado en el marco de mi trabajo, se ha puesto de relieve una compleja organización de fabricación de las chapas por la administración central, con un sistema de reutilización con fines económicos -en algunas han aparecido hasta seis capas de grabación- pero también con fines de autentificación, ya que cada serie recibía un sello particular. El control de identidad de los ciudadanos se hacía en el propio demos, en vinculación con la administración central.

Terminaré con el asunto de los lugares de utilización de los kleroteria, cuestión que plantea una serie de problemas. Las inscripciones que llevan los kleroteria bifrontes prescriben que se erijan las estelas en el santuario "en el que se procedió al sorteo". Conforme a las fuentes literarias, de época clásica (Esquines, Contra Ctesifonte 13; Constitutión de los Atenienses 62,1), que indican que las operaciones de sorteo (o parte de ellas) tenían lugar en el Theseion, y porque algunos ejemplares se hallaron al noreste del ágora clásica, se ha podido demostrar que la zona del Theseion arcaico siempre ha sido un lugar de sorteo, especialmente para el sorteo anual de los magistrados y del cuerpo de reserva de los 6.000 heliastas. Aunque se desplazara el ágora arcaica a la zona del Cerámico, el área del Pritaneo y del Theseion nunca dejó de ser un lugar de prácticas democráticas que, aunque parezca sorprendente, se reactivaron en el siglo II a.C., en un contexto de reafirmación de identidad nacional ${ }^{8}$, con la reorganización de los Teseia en 165 en honor del héroe fundador de la ciudad y según la tradición antigua, de la democracia. Se exponían en el Theseion, que había vuelto a ser un espacio emblemático de la antigua democracia, las inscripciones en honor a los agonotetas, lo

7 Esta réplica de kleroterion fue realizada por la Sociedad SNBR y financiada por el Departamento de la investigación, enseñanza superior y tecnología del Ministerio de Cultura, del Instituto de Ciencias humanas y sociales (InSHS) del CNRS y de la Maison de l'Orient et de la Méditerranée de Lyon. Se expuso por primera vez en el Salon Innovatives de Marsella el 17 y 18 de mayo de 2017.

8 Se debe a la vuelta a la prosperidad después de la paz de 167 y a la segunda dominación de Atenas sobre la liga de Delos. Esta época es marcada por dos fenómenos sociales de primer plano: la importancia dedicada a la institución de la efebia y la celebración de fiestas públicas, las Panateneas y los Teseia. 
que permite entender que aquella zona tenía cierta importancia y, de hecho, también los kleroteria que se encontraban allí, como símbolos tardíos de las herramientas de la época de la democracia del siglo IV.

En el ágora clásica, tenían lugar sorteos en el recinto del Bouleuterion, el llamado pritanikon, para la designación de la tribu que realizaba la pritanía y, más tarde, para el sorteo diario de los proedros, con kleroteria idóneos, cuyo número de columnas de ranuras correspondía al de las tribus del momento, ya que había desaparecido el sistema de cuotas de representación de los demos.

En lo que se refiere al sorteo en el tribunal del pueblo, aunque el texto de la Constitución de Atenas proporcione informaciones de primer orden sobre el proceso, la cuestión queda incierta en cuanto a los lugares en los que se realizaba. En la última década se han identificado como tribunales los vestigios al noreste del ágora bajo la Estoa de Átalo, distinguiendo dos fases principales: un conjunto de edificios que se construyeron poco a poco a finales del siglo $\mathrm{V}$ y a lo largo del siglo IV a.C. y un edificio único que se edificó en torno al año 300 a.C. La primera fase corresponde, más o menos, a la época del conjunto que Aristóteles llama de los dicasteria (o tribunales) y la hipótesis de que se haya podido organizar el espacio con dispositivos móviles y provisionales para acondicionar el acceso al tribunal, pasando el ciudadano sorteado por la entrada de su tribu y siguiendo el camino hacia el tribunal que le fuera asignado, también por sorteo, no es del todo descartable, pese a la falta de testimonios arqueológicos. No se han encontrado, pues, huellas de estructuras provisionales, como en el caso del supuesto perischoinisma, pero eso puede ser debido a las obras efectuadas a lo largo de los siglos en la zona. La identificación del edificio de la segunda fase, llamado Peristilo Rectangular en los estudios modernos, es todavía más problemática. Rhys Townsend (Townsend, 1995) restituye las diez entradas del tribunal mencionadas por Aristóteles en un pórtico donde no pueden caber, dejando además de lado el hecho de que nunca se terminó el edificio. La identificación de los edificios anteriores a la Estoa de Átalo es más que incierta y hasta ahora no se han hallado -salvo algunos tribunales de homicidio, fuera del ágora- ningún edificio que pueda corresponder a los escasos datos que proporcionan las fuentes en cuanto a la forma y ubicación del Tribunal popular de la época clásica.

Tal fue el caso de un edificio rectangular ubicado al suroeste del ágora que fue objeto de una errónea identificación por su tamaño $(26,5 \times 31)$, fecha, ya que se data a finales del siglo VI a.C., su ubicación, cerca del Bouleuterion, y el hecho de que se tratase de un recinto sin cubierta. Se consideró mucho tiempo que era la Heliaia, el Tribunal del pueblo, del que tenemos testimonios textuales que se remontan a finales del siglo VI. En 1998, R. Stroud publicó una ley sobre la tasas del grano datada en 374 a.C. y hallada en 1986, a partir de la cual argumenta que aquel edificio, llamado un tiempo "Peribolos Rectangular" por los arqueólogos, sería un santuario dedicado a Aiakos. Así aparece ahora en los planos del ágora.

Queda entonces buscar y encontrar la Heliaia, que algunos quieren ver a la fuerza en los vestigios del edificio A, cuyas dimensiones son parecidas a las del Aiakeion (41 x 22), el más antiguo del conjunto situado al noreste del ágora, remontándose a principios del siglo $\mathrm{V}$. 


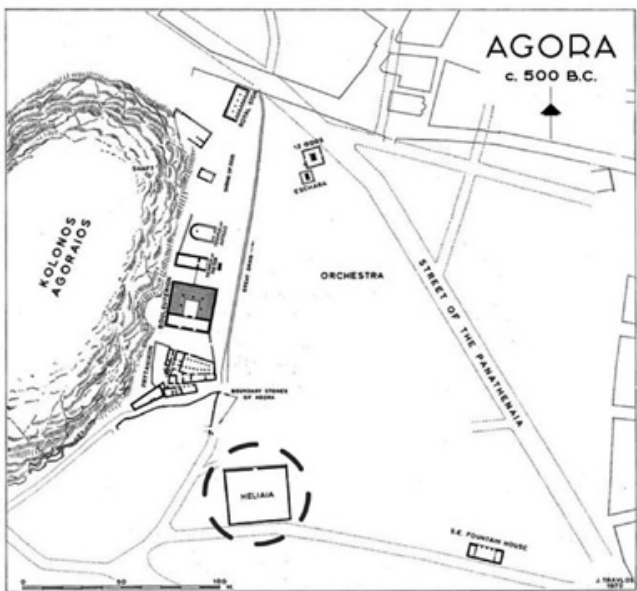

in THOMPSON H. A., WYCHERLEY R.E. (1972): The Athenian Agora: Results of Excavations, vol. XIV, The Agora of Athens : the history, shape and uses of an ancient city center, The American

School of Classical Studies, Princeton, pl. 4.

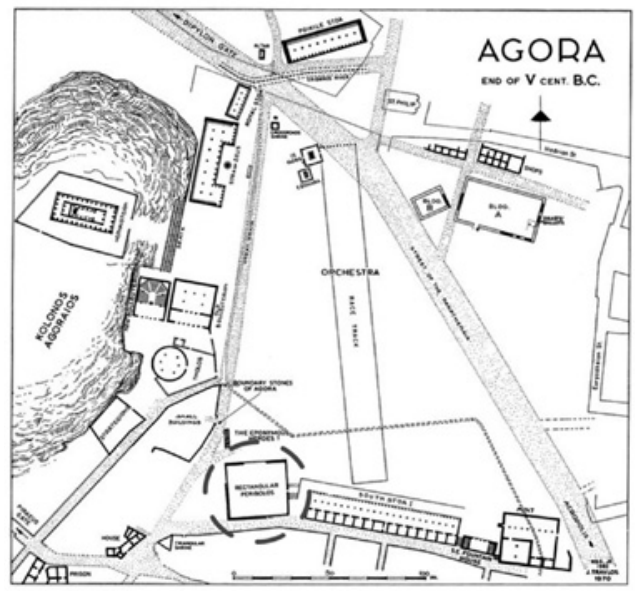

in TOWNSEND R. F. (1995) : The Athenian Agora: Results of Excavations, vol. XXVII, The East side of the Agora. The remains beneath the Stoa of Attalos, The American School of Classical Studies, Princeton, fig. 1 .

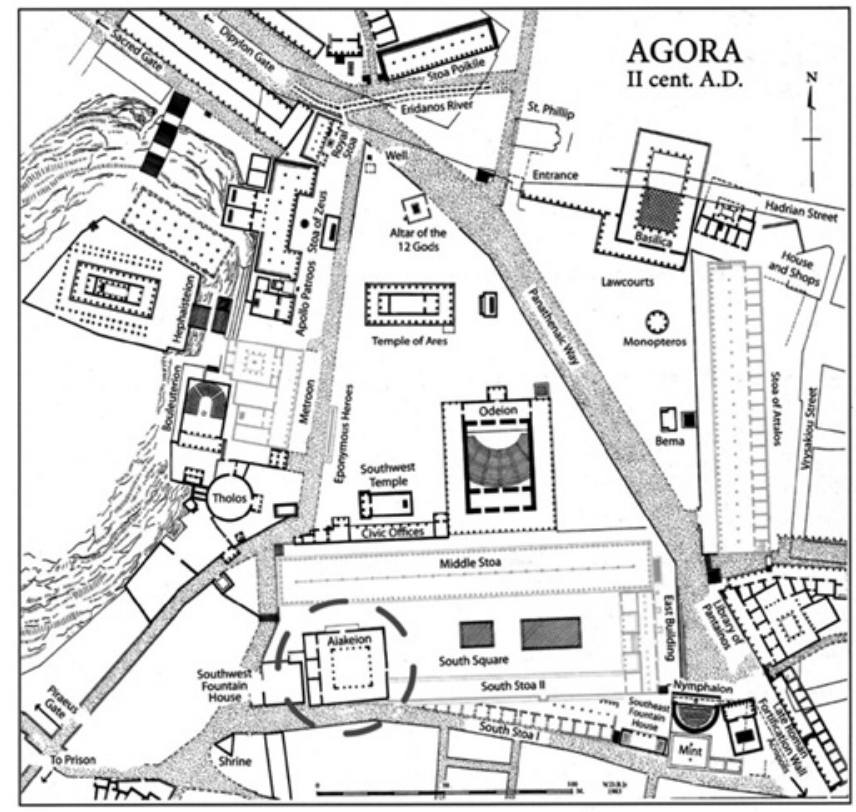

in C. A. Mauzy C. A. (2006), Agora Excavations 1931-2006, A

pictorial history, The American School of Classical Studies at Athens, Athènes, p. 9.

FIGURA 14:

La historia de la identificación de la Heliaia (L. López-Rabatel). 


\subsection{Recapitulando}

En este artículo hemos tratado pues de demostrar que las conclusiones a las que se llega en un momento determinado nunca se pueden considerar como definitivas. Aunque a día de hoy no aparezcan en Atenas vestigios arqueológicos que puedan revolucionar completamente la imagen que tenemos del advenimiento y desarrollo de la democracia, sí puede surgir algún que otro hallazgo que obligue a matizar hipótesis anteriores.

En cuanto a la esencia de la democracia y a su ideología, la arqueología no modifica en grandes líneas el conocimiento que se ha podido adquirir desde hace siglos a través de la lectura de los textos literarios y de las inscripciones. Algunos textos, como la archicitada Constitución de los Atenienses, han revolucionado la comprensión global de su funcionamiento. Sin embargo, en la mayoría de los casos, son ahora las inscripciones las que proporcionan nuevas informaciones, puesto que emanaban directamente del poder instituyente. Enfrentados a los datos textuales desde un punto de vista antropológico sobre la organización de los espacios internos o externos, los desplazamientos y los actos de los hombres, los hallazgos arqueológicos pueden colmar las lagunas de las informaciones literarias.

En lo que se refiere a la arquitectura de la democracia, la arqueología permite darse cuenta que Atenas, cuyo sistema democrático se ha difundido en el conjunto del mundo griego, presenta peculiaridades arquitectónicas muy interesantes y llamativas.

El ágora no es la prerrogativa de la democracia, bien lo sabemos, pero el mito de fundación de Atenas, vinculado al héroe Teseo, inscribe en el nuevo territorio cívico las fundaciones de la ideología democrática materializada en edificios emblemáticos como el Theseion y el Pritaneo. Después de la época arcaica, el primer espacio público que se organizó se debe a los Pisistrátidas, con la edificación de la Fuente Enneakrounos y del Altar de los Doce Dioses que forman parte de un proyecto global de embellecimiento de Atenas. Alrededor del año 500 se construyó una gran parte de los edificios más emblemáticos de la Atenas clásica: el Bouleuterion y el Tholos, y fuera del Ágora, este espacio tan singular llamado Pnyx, concebido para las reuniones del pueblo. Mientras que en Atenas el pueblo se reunía en el siglo $\mathrm{V}$ a.C. en el ágora para el ostracismo y en la Pnyx a lo largo de la democracia, se edificó en muchas ciudades un edificio idóneo llamado "ekklesiasterion".

Entre los edificios de la democracia, sólo estos tres tienen un destino propio pero el Bouleuterion y lo que era en otras ciudades el equivalente del Tholos, el Pritaneo, no son propios de la democracia. El ágora albergaba sobre todo edificios polivalentes como los pórticos. Lo más destacable es la falta hasta ahora de una identificación segura de tribunales y el recurso, para procedimientos fundamentales de la democracia, como el ostracismo o el sorteo, a dispositivos móviles y provisionales.

Así que, para concluir, de momento y con prudencia, parece que la democracia concibió un mobiliario democrático bastante sofisticado pero, aparte de la Pnyx, no se dotó de edificios emblemáticos y especialmente adaptados a sus procedimientos.

\section{Referencias}

Bishop, J. D. (1970): «The Cleroterium», JHS 90, Cambridge University Press, Londres, pp. 1-14. 
Boegehold, Alan L.; Camp, John McKesson; Crosby, Margaret; Lang, Mabel (1995): The Athenian Agora, vol. XXVIII, The Lawcourts at Athens, sites, buildings, equipment, procedure, and testimonia, The American School of Classical Studies, Princeton.

Camp, John McKesson (2015): «Excavations in the Athenian Agora, 2008-2012», Hesperia 84.3, The American School of Classical Studies, Athens, pp. 467-513.

Camp, John McKesson; Mauzy Craig. A. (2009): The Athenian Agora. New perspectives on an Ancient site, Zaberns Bildbände zur Archäologie, Mainz.

Camp, John McKesson (1998): The Athenian Agora: Excavations in the Heart of Classical Athens, Thames and Hudson, Londres, 1998.

Chandler, Richard (1806): Voyages dans l'Asie Mineure et en Grèce, II, trad. J.-P. Servois, Barbié du Bocage, París.

Clinton, Kevin (2005): Eleusis: the inscriptions on stone: documents of the sanctuary of the two goddesses and public documents of the deme, vol. IA (text)-IB (plates), Archaeological Society at Athens, Atenas.

Dontas, George S. (1983): «The True Aglaurion», Hesperia 52, The American School of Classical Studies, Atenas, pp. 48-63.

Dow, Sterling (1937): Prytaneis: a Study of the Inscriptions Honoring the Athenian Councillors, Hesperia Suppl. I, The American School of Classical Studies, Atenas.

Forsdyke, Sara (2005): Exile, Ostracism, and Democracy: The Politics of Expulsion in Ancient Greece, Princeton University Press, Princeton.

Hansen, Mogens Herman (2003) [1993]: La démocratie athénienne à l'époque de Démosthène. Structure, principes et idéologie, Les Belles Lettres, París (1a ed. en inglés en 1991).

Kroll, John H. (1972): Athenian Bronze Allotment Plates, Harvard University Press, Cambridge Massachusetts.

Lang, Mabel (1990): The Athenian Agora, vol. XXV, Ostraka, The American School of Classical Studies, Princeton.

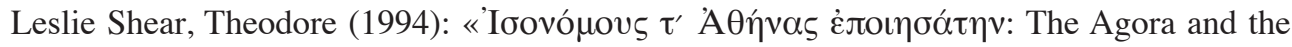
Democracy» in Coulson William D. E., Palagia Olga (éds), Leslie Shear Theodore: The Archaeology of Athens and Attica under the democracy: proceedings of an international conference ..., held at the American School of classical studies at Athens, December 4-6, 1992, Oxford.

Lipollis, Enzo (2006): «Lo spazio per votare e altre note di topografia sulle Agorai di Atene», ASAA 84-1, Bretschneider, Roma, pp. 37-61.

Lipollis, Enzo (en prensa): «Riunioni, operazioni di voto e agoni nell'agorà di Atene», in Borlenghi Aldo; Chillet Clément; Hollard Virginie; López-Rabatel Liliane; Moretti JeanCharles (dir), Voter dans l'Antiquité: pratiques, lieux et finalités en Grèce, à Rome et en Gaule, Maison de l'Orient et de la Méditerranée, Lyon, pp. 85-106.

López-Rabatel Liliane (2011): Klèrôtèria. Le tirage au sort dans le monde grec: machines, institutions et usages, 2 vol., tesis doctoral, Université Lyon 2 (inédita).

López-Rabatel Liliane (en prensa a): «Le vote dans le monde grec: procédures et équipement», in Borlenghi Aldo; Chillet Clément; Hollard Virginie; López-Rabatel Liliane; Moretti Jean-Charles (dir), Voter dans l'Antiquité: pratiques, lieux et finalités en Grèce, à Rome et en Gaule, Maison de l'Orient et de la Méditerranée, Lyon, pp. 53-84. 
López-Rabatel Liliane (en prensa b): «Mots et outils du tirage au sort», in López-Rabatel Liliane; Sintomer Yves: Tirage au sort et démocratie. Pratiques, instruments, théories. La Découverte, coll. Recherches, París.

Martin, Roland (1951): Recherches sur l'agora grecque, 1951, de Boccard, París.

Mauzy Craig, Agora Excavations 1931-2006, A pictorial history, p. 9, The American School of Classical Studies at Athens, Atenas, 2006.

Meritt, Benjamin Dean; Traill S. John (1974): The Athenian Agora: Results of Excavations, vol XV, Inscriptions: The Athenian Councillors, The American School of Classical Studies, Princeton.

Miller, Stephen Gaylord (1978): The Prytaneion: its function and architectural form. University of California press, Berkeley-Los Angeles-London.

Miller, Stephen Gaylord (1995): «Architecture as Evidence for the Identity of the Early Polis», in HANSEN, Mogens Herman; Copenhagen Polis Centre, Sources for the Ancient Greek City-State, Symposium August, 24-27 1994, Acts of the Copenhagen Polis Centre, Copenhagen-Munksgaard.

Moretti, Jean-Charles (en prensa): «La Pnyx, lieu de vote», in Borlenghi Aldo; Chillet Clément; Hollard Virginie; López-Rabatel Liliane; MORETTI Jean-Charles (dir), Voter dans l'Antiquité: pratiques, lieux et finalités en Grèce, à Rome et en Gaule, Maison de l'Orient et de la Méditerranée, Lyon, pp. 107-127.

Oikonomides, Al. Nicolaos (1964): The Two agoras in ancient Athens: a new commentary on their history and development: Topography and monuments, Argonaut Inc., Chicago, pp. 1-50: The agora in the old town).

Staveley E. Stuart (1972): Greek and Roman voting and Elections, Cornell University Press, Ithaca-Nueva York.

Thompson Homer A., Wycherley Richard Ernest (1972): The Athenian Agora: Results of Excavations, vol. XIV, The Agora of Athens: the history, shape and uses of an ancient city center, The American School of Classical Studies, Princeton.

Townsend Rhys. F. (1995): The Athenian Agora: Results of Excavations, vol. XXVII, The East side of the Agora, The remains beneath the Stoa of Attalos, The American School of Classical Studies, Princeton.

Valavanis, Panos (1999): Hysplex. The Starting Mechanism in Ancient Stadia. A Contribution to Ancient Greek Technology, Translated from the Greek and with an Appendix by Stephen G. Miller, University of California Publications, Classical Studies 36, University of California Press, Berkeley - Los Angeles - Londres.

Woodhead, A. Geoffrey (1997): The Athenian Agora: Results of Excavations vol. XV, Inscriptions: the decrees in The Athenian Agora, The American School of Classical Studies, Princeton.

Wycherley Richard Ernest (1957): The Athenian Agora: Results of Excavations, vol. III, Testimonia: Literary and Epigraphical Testimonia, The American School of Classical Studies, Princeton.

\section{Preliminary reports of de The Athenian Agora excavations:}

http://agora.ascsa.net/id/agora/report/2010\%20excavations?q=\&t=report\&v=list\&sort $=\& s=6$ 
http://agora.ascsa.net/id/agora/report/2011\%20excavations?q=\&t=report\&v=list\&sort $=\& s=5$

http://agora.ascsa.net/id/agora/report/2012\%20excavations?q=\&t=report\&v=list\&sort $=\& s=4$

http://agora.ascsa.net/id/agora/report/2013\%20excavations?q=\&t=report\&v=list\&sort $=\& s=3$ 